\title{
Effect of High-Flow Nasal Cannula on Thoraco-Abdominal Synchrony in Pediatric Subjects After Cardiac Surgery
}

\author{
Taiga Itagaki, Nobuto Nakanishi, Nao Okuda, Emiko Nakataki, Mutsuo Onodera, Jun Oto, and \\ Masaji Nishimura
}

\begin{abstract}
BACKGROUND: We previously reported the effects of high-flow nasal cannula (HFNC) oxygen therapy on thoraco-abdominal synchrony. This study was designed to clarify the effect of HFNC on thoraco-abdominal synchrony in pediatric subjects after cardiac surgery and to investigate HFNC optimal flow in this population. METHODS: Thoraco-abdominal synchrony was evaluated with respiratory inductive plethysmography. After extubation, we delivered oxygen via face mask for 30 min to subjects with mild to moderate respiratory failure. Each subject then randomly received either 1 or $2 \mathrm{~L} / \mathrm{kg} / \mathrm{min}$ via HFNC for $30 \mathrm{~min}$, followed by the other flow level via HFNC for $30 \mathrm{~min}$. After HFNC, face mask delivery was resumed. Rib cage and abdominal movement were converted into volumes and 2 quantitative indexes: maximum compartmental amplitude/tidal volume $\left(\mathbf{V}_{\mathrm{T}}\right)$ ratio and phase angle. RESULTS: Ten subjects of median (interquartile range) age $7(6-14)$ months and weighing $6.5(5.3-8.8) \mathrm{kg}$ were enrolled. Compared with the first delivery via face mask, breathing frequency, maximum compartmental amplitude/ $\mathrm{V}_{\mathrm{T}}$, phase angle, and minute volume significantly decreased at $2 \mathrm{~L} / \mathrm{kg} / \mathrm{min}(P<.05$ for all $)$ but not at $1 \mathrm{~L} / \mathrm{kg} / \mathrm{min} . P_{\mathrm{aCO}_{2}}$ did not differ among oxygen therapies. None of the measured variables differed between first and second face mask periods. CONCLUSIONS: After cardiac surgery, HFNC oxygen therapy at $2 \mathrm{~L} / \mathrm{kg} / \mathrm{min}$ improved thoraco-abdominal synchrony and decreased breathing frequency in pediatric subjects. (Clinical trial registration: UMIN000023426.) Key words: high-flow nasal cannula; neonates; thoracoabdominal synchrony; cardiac surgery; oxygen therapy. [Respir Care 2019;64(1):10-16. (C) 2019 Daedalus Enterprises]
\end{abstract}

\section{Introduction}

High-flow nasal cannula (HFNC) oxygen therapy is now a commonly used means of respiratory support for critically ill patients with respiratory failure. ${ }^{1-5}$ Despite its popularity, a convincing level of evidence is lacking in children. ${ }^{6-8}$ For subjects of all ages, a number of physiological advantages have been evaluated, including adequate humidification, ${ }^{9,10}$ positive airway pressure, ${ }^{11,12}$ washout of

Drs Itagaki, Nakanishi, Okuda, Nakataki, Onodera, and Nishimura are affiliated with Emergency and Critical Care Medicine, Tokushima University Graduate School, 3-18-15 Kuramoto, Tokushima 770-8503, Japan. Dr Oto is affiliated with the Department of Emergency and Disaster Medicine, Tokushima University Hospital, 2-50-1 Kuramoto, Tokushima 770-8503, Japan.

This study was supported by the Department of Emergency and Critical Care Medicine, Tokushima University Graduate School, Tokushima, Japan. The authors have disclosed no conflicts of interest. nasopharyngeal dead space, ${ }^{13,14}$ and stable $\mathrm{F}_{\mathrm{IO}_{2}} \cdot{ }^{10,15}$ The physiological effects of HFNC on children have been investigated mostly in premature infants, ${ }^{16,17}$ and data for other pediatric subjects are lacking. ${ }^{18}$

Patients with respiratory failure often exhibit impaired coordinated movement of the chest and abdomen, resulting in increased work of breathing. ${ }^{19,20}$ Previously, we studied the effect of HFNC on the movement of the chest and abdomen in adult subjects with mild to moderate respiratory failure. ${ }^{21}$ HFNC improved thoraco-abdominal synchrony and decreased breathing frequency while $\mathrm{P}_{a C O}$ was constant. Then we discussed washout of anatomical

\footnotetext{
Correspondence: Masaji Nishimura, Tokushima Prefectural Central Hospital, 1-10-3 Kuramoto-cho, Tokushima, 770-8539, Japan. E-mail: nmasaji@tph.gr.jp.
}

DOI: $10.4187 /$ respcare.06193 
dead space as a possible mechanism of the improved breathing pattern. Despite the wide use of HFNC in the management of critically ill children with respiratory insufficiency

\section{See the Related Editorial on Page 110}

from heart failure, cardiac surgery, and neuromuscular weakness as well as obstructive airway diseases, such as bronchiolitis, almost all of the published data for its effect on the breathing pattern of pediatric subjects has been derived from preterm infants..$^{20,22,23}$ In addition, the optimal flow for pediatric subjects has yet to be determined. HFNC generates positive airway pressure and may reduce work of breathing in a flow-dependent manner. ${ }^{8,11,16}$ However, the increase in airway pressure is unpredictable due to many factors, such as mouth opening, and may not have a linear relationship with set flow. ${ }^{24,25}$

The aim of this study was to determine whether HFNC improved thoraco-abdominal synchrony in pediatric subjects with mild to moderate respiratory failure after cardiac surgery. In addition, from the viewpoint of thoraco-abdominal synchrony, we examined the effect of flow level for pediatric subjects.

\section{Methods}

We conducted a prospective crossover study in a university hospital ICU. Ethical approval for this study (protocol number 1492) was provided by the ethics committee of Tokushima University Hospital. Written informed consent was obtained from parents.

\section{Subject Enrollment}

Pediatric subjects with body weight of $2-10 \mathrm{~kg}$ were surveyed. We included subjects with mild to moderate respiratory failure who presented with one or more of the following after extubation: $\mathrm{S}_{\mathrm{pO}_{2}}<95 \%$ without supplemental oxygen (for acyanotic heart disease); breathing frequency $>50$ breaths/min; asynchronous or paradoxical breathing pattern. The exclusion criteria were: mean blood pressure $<40 \mathrm{~mm} \mathrm{Hg}$ for neonates and $<50 \mathrm{~mm} \mathrm{Hg}$ for infants; $\mathrm{P}_{\mathrm{aO}_{2}} / \mathrm{F}_{\mathrm{IO}_{2}}<150 \mathrm{~mm} \mathrm{Hg}$ (for acyanotic heart disease); $\mathrm{pH}<7.2$ and $\mathrm{P}_{\mathrm{aCO}_{2}}>60 \mathrm{~mm} \mathrm{Hg}$; facial trauma or nasal obstruction; and inability to tolerate HFNC.

\section{Study Protocol}

Thoraco-abdominal movements were measured with respiratory inductive plethysmography (Inductotrace, Ambulatory Monitoring, Ardsley, New York) via 2 elastic transducers (Inductobands, Ambulatory Monitoring) placed

\section{QUICK LOOK}

\section{Current knowledge}

High-flow nasal cannula (HFNC) oxygen therapy improves thoraco-abdominal synchrony and reduces breathing frequency in adult patients with moderate hypoxemic respiratory failure. The impact of HFNC and flow level on breathing pattern has not been described in pediatric subjects.

\section{What this paper contributes to our knowledge}

In pediatric subjects with mild to moderate respiratory failure after cardiac surgery, HFNC oxygen therapy at $2 \mathrm{~L} / \mathrm{kg} / \mathrm{min}$ flow improved thoraco-abdominal synchrony by improving the phase angle and the ratio of maximum compartmental amplitude to tidal volume and decreasing breathing frequency.

around the thorax and abdomen to record changes in crosssectional area.

After extubation, we observed the subjects under ambient conditions for $5 \mathrm{~min}$. Each subject that met the inclusion criteria was enrolled into the study, and conventional oxygen therapy was applied to deliver oxygen via a loosely attached standard face mask (OX-130, Atom Medical, Saitama, Japan), at $0-3 \mathrm{~L} / \mathrm{min}$. Flow was titrated to keep $\mathrm{S}_{\mathrm{pO}_{2}}$ at $\geq 95 \%$. After $30 \mathrm{~min}$, we measured thoraco-abdominal movement, heart rate, blood pressure, breathing frequency, and $\mathrm{S}_{\mathrm{pO}_{2}}$ and drew an arterial blood sample for blood gas analysis. We then applied the HFNC through a system composed of an air-oxygen blender (San-You Technology, Saitama, Japan), a heated humidifier (MR850, Fisher \& Paykel Healthcare, Auckland, New Zealand), a breathing circuit (RT330, Fisher \& Paykel Healthcare), and a nasal cannula (OPT312/314/316, Fisher \& Paykel Healthcare). The breathing circuit included a heating wire and a pressure-relief valve to keep circuit pressure at $<45 \mathrm{~cm} \mathrm{H}_{2} \mathrm{O}$. Nasal cannula size was chosen to enable leakage at the nose by occluding approximately half the nares.

We evaluated the effect of HFNC at 2 flow levels within the maximum flow that the manufacturer claimed for each nasal cannula. HFNC flow of 1 and $2 \mathrm{~L} / \mathrm{kg} / \mathrm{min}$ were consecutively applied in digitally randomized order (ie, initial gas flow was $1 \mathrm{~L} / \mathrm{kg} / \mathrm{min}$ for $30 \mathrm{~min}$, followed by $2 \mathrm{~L} / \mathrm{kg} / \mathrm{min}$ for $30 \mathrm{~min}$ in some subjects, and vice versa for the others). At the end of each 30-min protocol, we measured thoracoabdominal movement, heart rate, blood pressure, breathing frequency, and $\mathrm{S}_{\mathrm{pO}_{2}}$ and drew arterial blood for blood gas analysis. After the HFNC protocols, conventional oxygen therapy was resumed, and the same measurements were taken after $30 \mathrm{~min}$. The study was stopped 


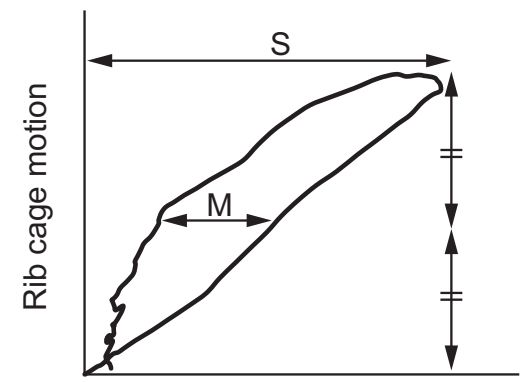

Abdominal motion

Fig. 1. Konno-Mead diagram of abdominal motion versus rib cage motion. The phase angle $(\theta)$ is calculated according to the formula, $\theta=\sin ^{-1}(\mathrm{M} / \mathrm{S})$, where $\mathrm{M}$ is the horizontal distance on the KonnoMead diagram at the midpoint between the maximal and minimal rib cage excursions, and $S$ is the maximal abdominal excursion. Asynchrony produces a wide open loop. Synchronous rib cage/abdominal motion has a $\theta$ of $0^{\circ}$, and paradoxical motion has a $\theta$ of $180^{\circ}$.

and routine management resumed if subjects revealed intolerance for HFNC, severe upper-airway obstruction, or acidosis $\mathrm{pH}<7.3$ with $\mathrm{P}_{\mathrm{aCO}_{2}}>50 \mathrm{~mm} \mathrm{Hg}$.

\section{Measurement of Thoraco-Abdominal Movement}

We calibrated respiratory inductive plethysmography using the qualitative diagnostic calibration technique described by Sackner et $\mathrm{al}^{26}$ The motions of the rib cage and abdomen were evaluated from changes in the inductance of the transducers during respiratory support via oronasal mask and HFNC. Signals were recorded, and the data were later analyzed with a software application (WINDAQ, DATAQ Instruments, Akron, Ohio). The arithmetic sums of the maximal peak-to-trough amplitudes of rib cage and abdomen excursions represent the maximum compartmental amplitudes. The algebraic sum of rib cage and abdomen excursions represents the tidal volume $\left(\mathrm{V}_{\mathrm{T}}\right)$. We then calculated the ratio of maximum compartmental amplitude to $\mathrm{V}_{\mathrm{T}}$. Plotting abdominal motion against rib cage motion, we also created Konno-Mead diagrams. Phase angle $(\theta)$ was calculated using the formula $\theta=\sin ^{-1}(\mathrm{M} / \mathrm{S})$, where $\mathrm{M}$ is the horizontal distance on the Konno-Mead diagram at the midpoint between the maximal and minimal rib cage excursions, and $\mathrm{S}$ is the maximal abdomen excursion (Fig. 1). Near the end of each protocol, data for 3 consecutive stable breaths were selected, and the mean was used as a single value for final analysis.

\section{Statistical Analysis}

The data, collected for 4 protocols (conventional oxygen therapy, HFNC $1 \mathrm{~L} / \mathrm{kg} / \mathrm{min}$, HFNC $2 \mathrm{~L} / \mathrm{kg} / \mathrm{min}$, and conventional oxygen therapy) were analyzed among all subjects by repeated measures of analysis of variance with
Table 1. Subject Characteristics

\begin{tabular}{|c|c|}
\hline Characteristics & Values \\
\hline Age, median (IQR) months & $7(6-14)$ \\
\hline Male/female, $n$ & $3 / 7$ \\
\hline Body weight, median (IQR) g & $6,527(5,288-8,788)$ \\
\hline Height, median (IQR) cm & $63(59-74)$ \\
\hline \multicolumn{2}{|l|}{ Surgery, $n$} \\
\hline VSD closure & 4 \\
\hline Glenn shunt & 2 \\
\hline Pulmonary artery banding & 1 \\
\hline Pulmonary artery debanding & 1 \\
\hline Coronary artery reconstruction & 1 \\
\hline ASD closure & 1 \\
\hline Length of mechanical ventilation, median (IQR) d & $7(3-10)$ \\
\hline $\mathrm{pH}$ before extubation, median (IQR) & $7.46(7.43-7.50)$ \\
\hline $\mathrm{P}_{\mathrm{aCO}_{2}}$ before extubation, median (IQR) $\mathrm{mm} \mathrm{Hg}$ & $32.1(31.2-37.7)$ \\
\hline $\mathrm{F}_{\mathrm{IO}_{2}}$ before extubation, median (IQR) & $0.23(0.21-0.25)$ \\
\hline \multicolumn{2}{|l|}{ Inclusion criteria, $n$} \\
\hline Hypoxia $\left(\mathrm{S}_{\mathrm{pO}_{2}}<95 \%\right)$ & 1 \\
\hline Tachypnea ( $>50$ breaths/min) & 2 \\
\hline Abnormal breathing pattern & 7 \\
\hline \multicolumn{2}{|c|}{$\begin{array}{l}N=10 . \text { Data are expressed as median (interquartile range) unless otherwise indicated. } \\
\text { IQR = interquartile range } \\
\text { VSD = ventricular septal defect } \\
\text { ASD }=\text { atrial septal defect }\end{array}$} \\
\hline
\end{tabular}

multiple comparisons for effect over time. Statistical calculations were carried out with statistics software (SPSS 11.0.1, SPSS, Chicago, Illinois). Data are expressed as mean $(95 \% \mathrm{CI})$ unless otherwise indicated. $P<.05$ was considered statistically significant.

\section{Results}

A total of 12 subjects who met inclusion criteria were enrolled in the study. Two subjects were subsequently excluded because they were overly restless, preventing respiratory inductive plethysmography measurements, reducing the study population to 10 . Two excluded subjects were observed under conventional oxygen therapy and never experienced further respiratory management. None of the remaining subjects experienced severe upper-airway obstruction or acidosis. We did not observe any apparent harm associated with treatment. Details of each subject are summarized in Table 1 . The median (interquartile range) age was 7 (6-14) months. Body weight was 6,527 (5,288$8,788) \mathrm{g}$, and 7 subjects $(70 \%)$ were female. The most common inclusion criterion was asynchronous or paradoxical breathing pattern $(70 \%)$.

Table 2 shows variables measured during conventional and HFNC oxygen therapy for all subjects; changes in values over time are shown in Figures 2 and 3. Compared with the first period of conventional delivery, statistically 
Table 2. Measurement Variables During Conventional Oxygen Therapy and Different Levels of High-Flow Nasal Cannula Delivery

\begin{tabular}{|c|c|c|c|c|}
\hline Variables & Control 1 & HFNC $1 \mathrm{~L} / \mathrm{kg} / \mathrm{min}$ & HFNC $2 \mathrm{~L} / \mathrm{kg} / \mathrm{min}$ & Control 2 \\
\hline Heart rate, beats/min & $134(124-143)$ & $137(121-153)$ & $138(123-153)$ & $136(120-152)$ \\
\hline Breathing frequency, breaths/min & $37(33-41)$ & $35(31-39)$ & $33(28-33)^{*}$ & $36(31-42) \dagger$ \\
\hline $\mathrm{V}_{\mathrm{T}}(\mathrm{vs}$ control 1$), \%$ & 100 & $96(63-129)$ & $101(75-127)$ & $104(72-135)$ \\
\hline Minute volume, $\mathrm{mL} / \mathrm{kg}$ & $303(223-383)$ & $245(185-306)$ & $242(191-293) *$ & $261(214-309)$ \\
\hline Phase angle, degrees & $32(20-45)$ & $21(14-29)$ & $19(10-28)^{*}$ & $22(14-30)$ \\
\hline $\mathrm{MCA} / \mathrm{V}_{\mathrm{T}}$ & $1.07(1.02-1.12)$ & $1.03(1.01-1.06)$ & $1.03(1.01-1.05)^{*}$ & $1.04(1.01-1.07)$ \\
\hline $\mathrm{P}_{\mathrm{aCO}_{2}}, \mathrm{~mm} \mathrm{Hg}$ & $36(33-39)$ & $35(32-38)$ & $34(31-38)$ & $35(32-37)$ \\
\hline $\begin{array}{l}\text { Data are mean }(95 \% \mathrm{CI}) . \\
* P<.05 \text { versus control } 1 . \\
\dagger P<.05 \text { versus } 2 \mathrm{~L} / \mathrm{kg} / \mathrm{min} . \\
\text { HFNC }=\text { high-flow nasal cannula } \\
\mathrm{V}_{\mathrm{T}}=\text { tidal volume } \\
\mathrm{MCA} / \mathrm{V}_{\mathrm{T}}=\text { ratio of maximum compartment }\end{array}$ & tidal volume & & & \\
\hline
\end{tabular}

significant decreases in $\mathrm{HFNC}$ at $2 \mathrm{~L} / \mathrm{kg} / \mathrm{min}$, but not in HFNC at $1 \mathrm{~L} / \mathrm{kg} / \mathrm{min}$, were detected in breathing frequency (mean [95\% CI], 33 [28-33] vs 37 [33-41] breaths/min,
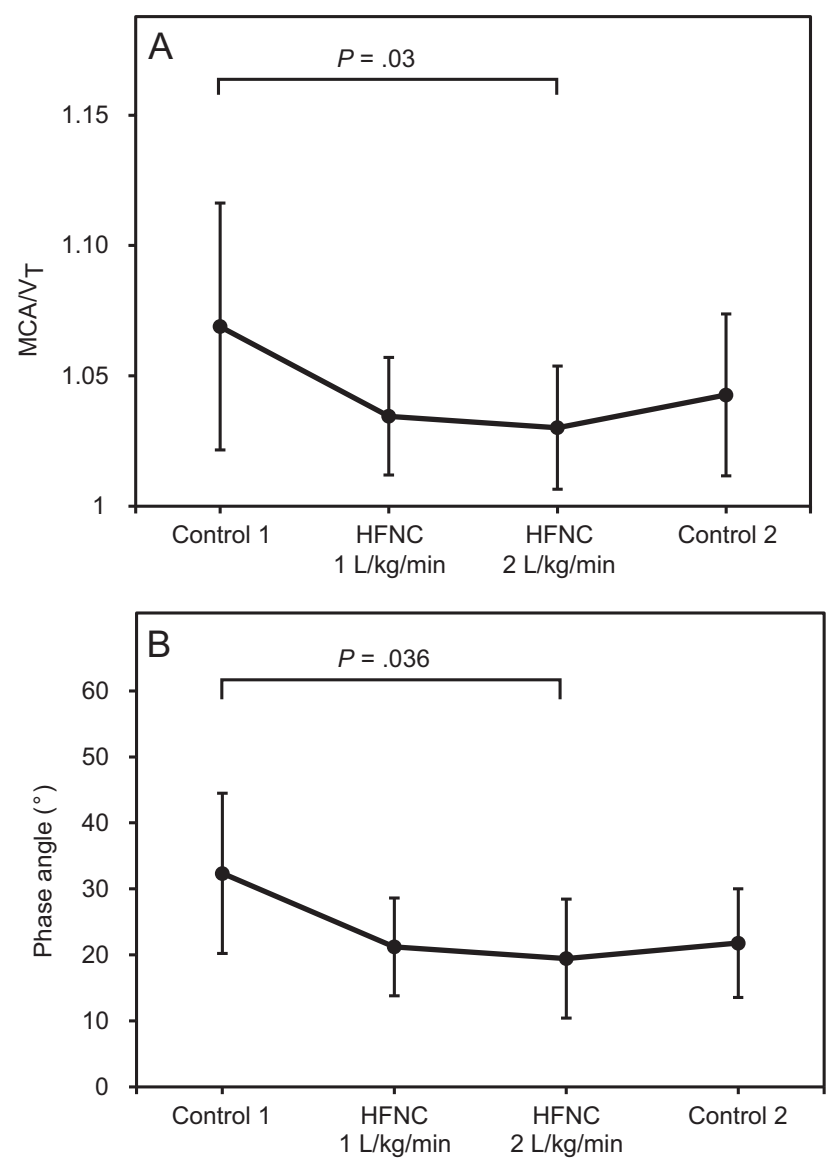

Fig. 2. Changes in variables related to thoraco-abdominal synchrony for conventional oxygen therapy and different levels of high-flow nasal cannula (HFNC) delivery. A: Ratio of maximum compartmental amplitude to tidal volume $\left(M C A / V_{T}\right)$. B: Phase angle. Both parameters did not differ between controls. Data are expressed as means and $95 \% \mathrm{Cl}$.
$P=.01)$, maximum compartmental amplitude $/ \mathrm{V}_{\mathrm{T}}(1.03$ [1.01-1.05] vs $1.07[1.02-1.12], P=.03)$, phase angle $\left(19^{\circ}\left[10-28^{\circ}\right]\right.$ vs $\left.32^{\circ}\left[20-45^{\circ}\right], P=.036\right)$, and minute volume (242 [191-293] vs $303 \quad$ [223-383] $\mathrm{mL} / \mathrm{kg}$, $P=.037)$. No statistically significant difference in any variable was found after comparing data for HFNC at 1 and $2 \mathrm{~L} / \mathrm{kg} / \mathrm{min}$. During the second period of conventional delivery, breathing frequency was statistically significantly higher than during $2 \mathrm{~L} / \mathrm{kg} / \mathrm{min}$ (36 [31-42] vs 33 [28-33] breaths/min, $P=.03$ ). Maximum compartmental amplitude $/ \mathrm{V}_{\mathrm{T}}$, phase angle, and minute volume, however, did not change after final discontinuation of HFNC. $\mathrm{P}_{\mathrm{aCO}_{2}}$ was similar during each protocol. No statistically significant difference in any variable was found after comparing data for the first and second periods of conventional delivery.

\section{Discussion}

The major finding of our study is that, for pediatric subjects after cardiac surgery, HFNC oxygen therapy at flow $2 \mathrm{~L} / \mathrm{kg} / \mathrm{min}$ improved thoraco-abdominal synchrony and reduced breathing frequency. To our knowledge, this is the first crossover study to investigate the effect of different HFNC flows on thoraco-abdominal synchrony.

\section{Effect of HFNC on Thoraco-Abdominal Synchrony}

Despite an open system, HFNC generates positive airway pressure in a flow-dependent manner. ${ }^{8,11,16}$ Moreover, unidirectional high gas flow toward the lung during the inspiratory phase offloads the diaphragm and reduces work of breathing. ${ }^{16,19,27,28}$ Both positive airway pressure and better matching of the patient's inspiratory flow are supposed to eliminate the rib cage lag after the abdominal motion, which is often seen in patients with respiratory failure. ${ }^{20}$ Reduced nasopharyngeal dead space may be another possible reason for the improvement of thoraco-ab- 

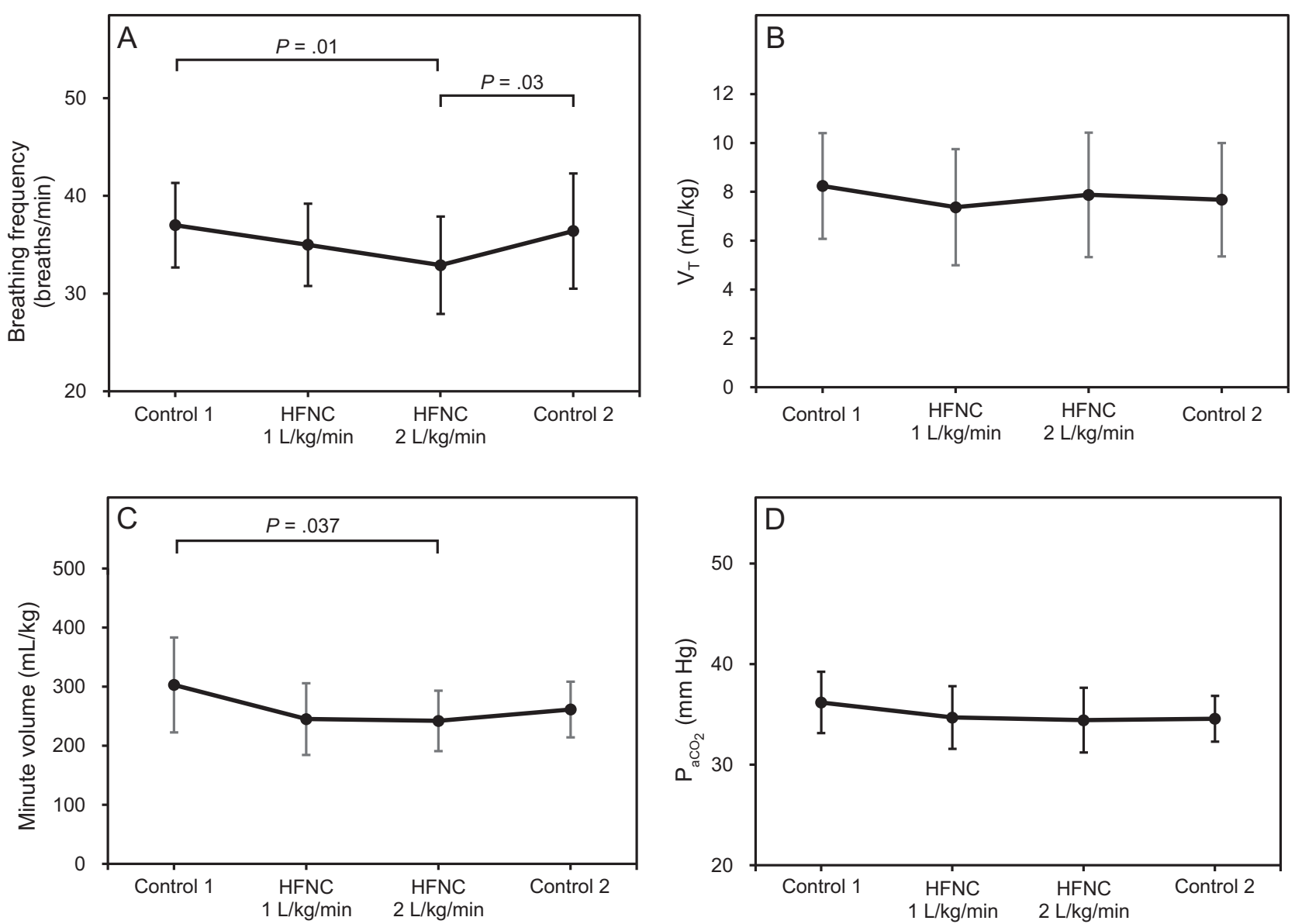

Fig. 3. Changes in ventilation variables among conventional oxygen therapy and different levels of high-flow nasal cannula (HFNC) delivery. A: Breathing frequency. B: Tidal volume $\left(\mathrm{V}_{\mathrm{T}}\right)$. C: Minute volume. D: $\mathrm{P}_{\mathrm{acO}_{2}}$. All parameters did not differ between controls. Data are expressed as means and $95 \% \mathrm{Cl}$.

dominal synchrony. As seen in our adult study, ${ }^{21}$ we observed decreased minute volume and breathing frequency, without alteration of $\mathrm{P}_{\mathrm{aCO}_{2}}$ during HFNC. It is possible that HFNC improved breathing pattern through washout of airway dead space.

Our finding is also consistent with other studies reporting the favorable effects of HFNC on the breathing pattern of preterm infants. Studying preterm infants requiring supplemental oxygen but not mechanical ventilation, Locke et $\mathrm{al}^{22}$ found a significant flow-dependent decrease in phase angle from 80 to $53^{\circ}$ when oxygen was administered through a large-bore nasal cannula at $0.5-2 \mathrm{~L} / \mathrm{min}$. In a study of neonates, including some who had undergone mechanical ventilation, de Jongh et $\mathrm{al}^{20}$ observed a small decrease in phase angle from 115 to $87^{\circ}$ when HFNC flow increased from 3 to $5 \mathrm{~L} / \mathrm{min}$. Compared with studies in preterm infants, we observed a lower phase angle, possibly because we studied older subjects with better lung mechanics and chest wall stability. ${ }^{29}$ Rather than the small airway obstruction seen in premature infants, ${ }^{30}$ our population had decreased lung and chest wall compliance in- duced by edema after cardiac surgery responsive to greater positive airway pressure. Pham et $\mathrm{al}^{16}$ found that HFNC reduced work of breathing both in infants with bronchiolitis and in infants with cardiac problems, although the effects were less prominent in the latter. We can conclude that there are some differences in the mechanisms involved in the improvement of thoraco-abdominal synchrony in preterm infants and in our population.

\section{Optimal Flow During HFNC}

HFNC up to $2 \mathrm{~L} / \mathrm{kg} / \mathrm{min}$ could be safely applied, and at this flow, thoraco-abdominal synchrony was statistically significantly better than with conventional oxygen therapy. Testing HFNC flows of $0.3,0.6$, and $1.3 \mathrm{~L} / \mathrm{kg} / \mathrm{min}$, Locke et $\mathrm{al}^{22}$ observed linear phase angle improvement but were unable to detect a value at which improvement ceased. Meanwhile, testing HFNC flows of 2.0 and $3.3 \mathrm{~L} / \mathrm{kg} / \mathrm{min}$, de Jongh et $\mathrm{al}^{20}$ discerned only a slight decrease in phase angle. We refrained from testing flow at more than the recommended level of $2 \mathrm{~L} / \mathrm{kg} / \mathrm{min}$, although an observa- 
tional study on pediatric HFNC noted flows up to $3 \mathrm{~L} / \mathrm{kg} /$ min. ${ }^{31}$ Within safe limits, higher flows that de Jongh et al applied ${ }^{20}$ should be tested to provide additional evidence.

In a lung-injured animal model, Frizzola et $\mathrm{al}^{14}$ found that the effect of increasing $\mathrm{HFNC}$ flow on $\mathrm{CO}_{2}$ removal was independent of mouth opening and tracheal pressure. $\mathrm{P}_{\mathrm{aCO}}$, plateaued, however, once flow reached a certain level, which may be the point at which all dead space is flushed out. Airway pressure also rises flow-dependently during HFNC in adults, ${ }^{11,32,33}$ children, ${ }^{12,34}$ and preterm infants. ${ }^{14,34,35}$ In a recent adult study, Mauri et al ${ }^{36}$ found that although pressure-related effects, such as oxygenation, end-expiratory lung volume, and lung mechanics, improved linearly, increasing HFNC flow exponentially decreased the work of breathing and minute ventilation, and most of the effects were already obtained at a minimum flow of $30 \mathrm{~L} / \mathrm{min}$. The improvement of thoraco-abdominal synchrony over time may possibly be linked to those linear effects, which are related to increasing airway pressure. Even so, we must remain aware that the effects, as well as other factors, can be largely influenced by cannula size, ${ }^{29,35}$ mouth leakage, ${ }^{11,29}$ and, as Mauri et al ${ }^{36}$ observed, significant individual variability of flow, which accounted for the largest physiological improvements.

\section{Strengths and Limitations of This Study}

We designed the study so as to both determine and compare the effects of 2 levels of HFNC flow on thoracoabdominal synchrony for each subject. This made it possible to conduct within-subject comparisons, rather than intergroup comparisons, which would have necessitated a much larger sample size. Using a crossover study design also allowed us to minimize the sequence effect of the 2 different HFNC flows. In theory, flow per se could have contributed to the improvement of breathing pattern.

There are several limitations to this study. First, even in a crossover study, results from a sample of only 10 subjects with mild to moderate respiratory failure is inadequate for broad extrapolation. Studies using larger sample sizes are necessary to determine the optimal level of HFNC and its clinical importance. Second, our population, age 0-28 months, was also age-limited. Because the airway anatomy and respiratory mechanics of babies differ substantially from those of older infants and pre-teen children, extrapolation may not be prudent. Even so, there is no evident relationship between baseline phase angle and age. Third, during each protocol, we collected data from only 3 consecutive breaths, and there is no guarantee that all of these samples were typical; on the other hand, when the samples were collected, 30 min into each protocol, parameters had mostly stabilized.

\section{Clinical Implications}

In this study, $\mathrm{HFNC}$ at $2 \mathrm{~L} / \mathrm{kg} / \mathrm{min}$ flow improved breathing pattern in pediatric cardiac subjects. Additionally, we observed a significant decrease in breathing frequency with HFNC. Indeed, reduced breathing frequency has been the most salient beneficial clinical effect of HFNC in previous studies for both adults ${ }^{21,37-40}$ and pediatric subjects. ${ }^{18,41} \mathrm{In}$ an adult clinical study, Sztrymf et $\mathrm{al}^{37}$ concluded that absence of a decrease in respiratory frequency and persistent paradoxical breathing pattern as well as lower oxygenation after HFNC initiation were key and often early observable signs of impending respiratory failure. Our findings indicate that careful physical examination may also be valuable in children as a surrogate as HFNC flow levels are adjusted and used to recognize success or failure of this therapy.

\section{Conclusions}

In pediatric subjects after cardiac surgery, HFNC oxygen therapy at $2 \mathrm{~L} / \mathrm{kg} / \mathrm{min}$ flow improved thoraco-abdominal synchrony and decreased breathing frequency. Further studies are required to ascertain optimal flow levels and to predict which types of patients will derive the most benefit from HFNC.

\section{REFERENCES}

1. Nishimura M. High-flow nasal cannula oxygen therapy in adults: physiological benefits, indication, clinical benefits, and adverse effects. Respir Care 2016;61(4):529-541.

2. Levy SD, Alladina JW, Hibbert KA, Harris RS, Bajwa EK, Hess DR. High-flow oxygen therapy and other inhaled therapies in intensive care units. Lancet 2016;387(10030):1867-1878.

3. Nedel WL, Deutschendorf C, Moraes Rodrigues Filho E. High-flow nasal cannula in critically ill subjects with or at risk for respiratory failure: a systematic review and meta-analysis. Respir Care 2017; 62(1):123-132.

4. Ward JJ. High-flow oxygen administration by nasal cannula for adult and perinatal patients. Respir Care 2013;58(1):98-122.

5. Frat JP, Thille AW, Mercat A, Girault C, Ragot S, Perbet S, et al. High-flow oxygen through nasal cannula in acute hypoxemic respiratory failure. N Engl J Med 2015;372(23):2185-2196.

6. Baudin F, Pouyau R. High-flow nasal cannula in the pediatric ICU: popular or efficient? Respir Care 2017;62(8):1116-1117.

7. Ramnarayan P, Schibler A. Glass half empty or half full? The story of high-flow nasal cannula therapy in critically ill children. Intensive Care Med 2017;43(2):246-249.

8. Hutchings FA, Hilliard TN, Davis PJ. Heated humidified high-flow nasal cannula therapy in children. Arch Dis Child 2015;100(6):571575 .

9. Chikata Y, Izawa M, Okuda N, Itagaki T, Nakataki E, Onodera M, et al. Humidification performance of two high-flow nasal cannula devices: a bench study. Respir Care 2014;59(8):1186-1190.

10. Chikata Y, Ohnishi S, Nishimura M. Humidity and inspired oxygen concentration during high-flow nasal cannula therapy in neonatal and infant lung models. Respir Care 2017;62(5):532-537. 
11. Parke RL, McGuinness SP. Pressures delivered by nasal high flow oxygen during all phases of the respiratory cycle. Respir Care 2013; 58(10):1621-1624.

12. Urbano J, del Castillo J, López-Herce J, Gallardo JA, Solana MJ, Carrillo Á. High-flow oxygen therapy: pressure analysis in a pediatric airway model. Respir Care 2012;57(5):721-726.

13. Möller W, Celik G, Feng S, Bartenstein P, Meyer G, Oliver E, et al. Nasal high flow clears anatomical dead space in upper airway models. J Appl Physiol 2015;118(12):1525-1532.

14. Frizzola M, Miller TL, Rodriguez ME, Zhu Y, Rojas J, Hesek A, et al. High-flow nasal cannula: impact on oxygenation and ventilation in an acute lung injury model. Pediatr Pulmonol 2011;46(1): 67-74.

15. Chikata $\mathrm{Y}$, Onodera $\mathrm{M}$, Oto J, Nishimura $\mathrm{M} . \mathrm{F}_{\mathrm{IO}_{2}}$ in an adult model simulating high-flow nasal cannula therapy. Respir Care 2017;62(2): 193-198.

16. Pham TM, O'Malley L, Mayfield S, Martin S, Schibler A. The effect of high flow nasal cannula therapy on the work of breathing in infants with bronchiolitis. Pediatr Pulmonol 2015;50(7):713-720.

17. Schibler A, Pham TM, Dunster KR, Foster K, Barlow A, Gibbons K, Hough JL. Reduced intubation rates for infants after introduction of high-flow nasal prong oxygen delivery. Intensive Care Med 2011; 37(5):847-852.

18. Milési C, Baleine J, Matecki S, Durand S, Combes C, Novais AR, Cambonie G. Is treatment with a high flow nasal cannula effective in acute viral bronchiolitis? A physiologic study. Intensive Care Med 2013;39(6):1088-1094.

19. Tobin MJ, Jenouri G, Lind B, Watson H, Schneider A, Sackner MA. Validation of respiratory inductive plethysmography in patients with pulmonary disease. Chest 1983;83(4):615-620.

20. de Jongh BE, Locke R, Mackley A, Emberger J, Bostick D, Stefano $\mathrm{J}$, et al. Work of breathing indices in infants with respiratory insufficiency receiving high-flow nasal cannula and nasal continuous positive airway pressure. J Perinatol 2014;34(1):27-32.

21. Itagaki T, Okuda N, Tsunano Y, Kohata H, Nakataki E, Onodera M, et al. Effect of high-flow nasal cannula on thoraco-abdominal synchrony in adult critically ill patients. Respir Care 2014;59(1):70-74.

22. Locke RG, Wolfson MR, Shaffer TH, Rubenstein SD, Greenspan JS. Inadvertent administration of positive end-distending pressure during nasal cannula flow. Pediatrics 1993;91(1):135-138.

23. Saslow JG, Aghai ZH, Nakhla TA, Hart JJ, Lawrysh R, Stahl GE, Pyon KH. Work of breathing using high-flow nasal cannula in preterm infants. J Perinatol 2006;26(8):476-480.

24. Nielsen KR, Ellington LE, Gray AJ, Stanberry LI, Smith LS, DiBlasi RM. Effect of high-flow nasal cannula on expiratory pressure and ventilation in infant, pediatric, and adult models. Respir Care 2018; 63(2):147-157.

25. Luo JC, Lu MS, Zhao ZH, Jiang W, Xu B, Weng L, et al. Positive end-expiratory pressure effect of 3 high-flow nasal cannula devices. Respir Care 2017;62(7):888-895.

26. Sackner MA, Watson H, Belsito AS, Feinerman D, Suarez M, Gonzalez G, et al. Calibration of respiratory inductive plethysmograph during natural breathing. J Appl Physiol 1989;66(1):410-420.
27. Dysart K, Miller TL, Wolfson MR, Shaffer TH. Research in high flow therapy: mechanisms of action. Respir Med 2009;103(10):14001405.

28. Lee JH, Rehder KJ, Williford L, Cheifetz IM, Turner DA. Use of high flow nasal cannula in critically ill infants, children, and adults: a critical review of the literature. Intensive Care Med 2013;39(2): 247-257.

29. Sivieri EM, Gerdes JS, Abbasi S. Effect of HFNC flow rate, cannula size, and nares diameter on generated airway pressures: an in vitro study. Pediatr Pulmonol 2013;48(5):506-514.

30. Gappa M, Pillow JJ, Allen J, Mayer O, Stocks J. Lung function tests in neonates and infants with chronic lung disease: Lung and chestwall mechanics. Pediatr Pulmonol 2006;41(4):291-317.

31. Coletti KD, Bagdure DN, Walker LK, Remy KE, Custer JW. High flow nasal cannula utilization in pediatric critical care. Respir Care 2017;62(8):1023-1029.

32. Ritchie JE, Williams AB, Gerard C, Hockey H. Evaluation of a humidified nasal high-flow oxygen system, using oxygraphy, capnography and measurement of upper airway pressures. Anaesth Intensive Care 2011;39(6):1103-1110.

33. Parke RL, Bloch A, McGuinness SP. Effect of very-high-flow nasal therapy on airway pressure and end-expiratory lung impedance in healthy volunteers. Respir Care 2015;60(10):1397-1403.

34. Hasan RA, Habib RH. Effects of flow rate and airleak at the nares and mouth opening on positive distending pressure delivery using commercially available high-flow nasal cannula systems: a lung model study. Pediatr Crit Care Med 2011;12(1):e29-e33.

35. Volsko TA, Fedor K, Amadei J, Chatburn RL. High flow through a nasal cannula and CPAP effect in a simulated infant model. Respir Care 2011;56(12):1893-1900.

36. Mauri T, Alban L, Turrini C, Cambiaghi B, Carlesso E, Taccone P, et al. Optimum support by high-flow nasal cannula in acute hypoxemic respiratory failure: effects of increasing flow rates. Intensive Care Med 2017;43(10):1453-1463.

37. Sztrymf B, Messika J, Bertrand F, Hurel D, Leon R, Dreyfuss D, Ricard JD. Beneficial effects of humidified high flow nasal oxygen in critical care patients: a prospective pilot study. Intensive Care Med 2011;37(11):1780-1786.

38. Sztrymf B, Messika J, Mayot T, Lenglet H, Dreyfuss D, Ricard JD. Impact of high-flow nasal cannula oxygen therapy on intensive care unit patients with acute respiratory failure: a prospective observational study. J Crit Care 2012;27(3):324.e9-e13.

39. Roca O, Riera J, Torres F, Masclans JR. High-flow oxygen therapy in acute respiratory failure. Respir Care 2010;55(4):408-413.

40. Corley A, Caruana LR, Barnett AG, Tronstad O, Fraser JF. Oxygen delivery through high-flow nasal cannulae increase end-expiratory lung volume and reduce respiratory rate in post-cardiac surgical patients. Br J Anaesth 2011;107(6):998-1004.

41. Lampland AL, Plumm B, Meyers PA, Worwa CT, Mammel MC. Observational study of humidified high-flow nasal cannula compared with nasal continuous positive airway pressure. J Pediatr 2009;154(2):177-182.

This article is approved for Continuing Respiratory Care Education credit. For information and to obtain your CRCE

(free to AARC members) visit www.rcjournal.com

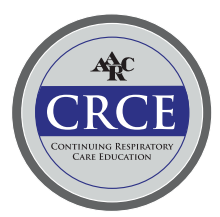

